\title{
A Holistic Sustainable Finance Model for the Sustainable Capital Market
}

\author{
Anastasios Sepetis \\ Department of Business Administration, University of West Attica, Egaleo, Greece \\ Email: tsepet@yahoo.com
}

How to cite this paper: Sepetis, A. (2020). A Holistic Sustainable Finance Model for the Sustainable Capital Market. Journal of Financial Risk Management, 9, 99-125. https://doi.org/10.4236/jfrm.2020.92006

Received: May 23, 2020

Accepted: June 6, 2020

Published: June 9, 2020

Copyright $(\odot 2020$ by author(s) and Scientific Research Publishing Inc. This work is licensed under the Creative Commons Attribution International License (CC BY 4.0).

http://creativecommons.org/licenses/by/4.0/

\begin{abstract}
This paper, has systematized the literature review, and with its critical view towards international and especially European sustainable finance policy and methodologies, has marked three important problems that affect up until today the design and implementation of environmental, social and sustainable policies in the sustainable financial performance of capital market. Environmental, social and sustainable performance measures, as well as the taxonomy system, the evaluation and notification of information that are related to the consequences of sustainable policies, represent a modern challenge for creating a completer methodology in the field of sustainable finance. In a practical level the challenge still remains: 1) if the policies, methodologies and researches in this category, allow researchers and financial stakeholders, as well as firms managers to follow and to evaluate sustainable finance in a reliable manner, 2) if the sustainable policies of firms are successful and recognized by the capital market. As every new scientific field, so "Sustainable Finance" must be framed with theories that should define the efficient operation of "Sustainable Market Capital" and get new holistic "Sustainable Finance model" created. The purpose of this paper is to define the theory of Sustainable Capital Market and the Holistic Sustainable Finance Models.
\end{abstract}

\section{Keywords}

Sustainable Finance, ESG Shareholder Value, Environmental and Social Responsibility Finance, Environmental Social and Governance (ESG) Models, Social Responsibility Investment, Sustainable Finance Long-Term Models

\section{Introduction}

In the capital market, the environmental, social and corporate governance, as well as the sustainable development policies and sustainable development goals 
are connected in multiple ways with the modern business strategy, through profit-cost policy, competitiveness and the shareholder value of firms. This is due to different motives than the ones that lead financial public environmental and socially responsible institutional sustainable policies, where the basic goals are the service of the environmental, social or general public profit. Firms on the other hand, systematically try to succeed better financial results and respectively adapt to the new offer conditions of environmental resources and social responsibility. Moreover, they try to attract consumers and private institutional sustainable financial stakeholders and private sustainable investors. As a result sustainable firms, sustainable development goals and capital market connect unavoidably in an intensifying pace to the sustainable firms' strategy and sustainable financial stakeholders and progressively become its organic part.

The European Union and the UN, as well as other financial institutions (ex. Word Bank, OECD) interested in "Sustainable Finance", for fostering transparency and long-term taxonomy. Moreover, the capital market stakeholders and the leverage of financial and investing community for the implementation of environmental, social or sustainable management policies, as well as the financing of the firms sustainability, present the following common problem, as it is defined by the Action Plan for Sustainable Finance: While they recognize the existence of environmental, social and sustainable market tendency, they still do not provide sufficient answers up until now regarding the taxonomy that will define the harmonized financial methods and accounting standards that should be taken into consideration by the decision makers, in order the financial, investing and consulting community to evaluate if and in what extend a financial activity is sustainable. Moreover, the scientific research of this paper claims that a determinative theoretical financial framework of sustainable finance is demanded that will match with the realistic structure of the current financial market. Furthermore, a basic approach that would contribute to a more accurate display of the relations and the dynamics that are developed in this field, would be a commonly accepted definition of "Sustainable Capital Market".

In order to practice environmental, social or sustainable policy in the capital market, we can use the already known and tested financial method of environmental policy (ex. Energy tax) or the "holistic sustainable finance risk model" of financial policy, such as sustainable interest rate, that we suggest in the current paper. By using these financial methods, those responsible for the decision making in the capital market, will be able to negotiate and make prediction scenarios as to how sustainable finance policies affect the capital market. Following this financial methodological procedure, the basic capital market bodies, apart from rating the decision between alternative suggestions for the materialization or not of the sustainable financial policy, they can also choose a sustainable strategy based in two different holistic sustainable financial policies: 1) They can fluctuate the holistic sustainable financial risk methods that affect the market in total, according to the sustainable adjustment that they want to bring to the 
market, 2) They can participate in the decisions taken during the sustainable policy consultation procedure (ex. EU Action Plan for sustainable development finance or green agreement finance), decisions which are taken in order to accelerate the percentages of sustainable market adjustment to the best level of sustainable performance. Under this possibility of choices, the basic capital market bodies interfere in the potential procedure of sustainable performance calculation, in which the changes fluctuate during the year. Those changes are externally defined by different sustainable policies, such as the Paris Treaty and the 17 goals of Sustainable Development. This approach means that the society according to the worldwide situation/conditions, regulates its internal policies and creates sustainable innovations and strategies, such as the national strategy for sustainable development goals, in order to succeed a rate of sustainable performance (ex. The reduction of $\mathrm{CO}_{2}$ ). For example, when the policy makers wish to raise the environmental dimension of the market, then in the total sustainable performance risk index, we can reduce the sustainable interest rate that affects the environmental performance of a firm and retain stable the indexes that affect social protection and economic efficiency.

Sustainable finance is already a serious global environmental policy and social challenge, especially regarding climate change issues. It has concrete sustainable development goals, it is nevertheless relatively new and the Shareholders-financial Stakeholders, responsible for the capital market decision making, as well as the indirect Shareholders-Stakeholders, are possible to make serious mistakes, if their actions are not based in the proven theoretical and empirical research. The discussion regarding the sustainable capital market and sustainable finance develops in a progressive manner and pace. It has already well-determined sides that have produced almost clear, but also contradictive arguments. Neither financial science nor technology can change the inherent non-predictability of the future in relation to the sustainable finance of the capital market. Instead, they answer to the following question: "Which actions today should be recognized, taxonomized, evaluated, notified and lead the environmental, social and corporate governance issues with the greater success to the future that we wish?" The decision makers for sustainable finance goals and the proposed holistic sustainable financial model, once they recognize, taxonomize and evaluate the environmental, social and sustainable effects, will seek the plausible predictions in which a sustainable capital market would succeed or would fail.

In the literature review chapter of this paper, in a detailed and comprehensive way, a detailed analysis, description and criticism is made at the most important studies that correlate the environmental, social and sustainable policies with the capital market. The next chapter presents, evaluates and taxonomizes the results of the literature review and suggests a pioneer definition of "Sustainable Capital Market" and presents a theoretical holistic framework of the Sustainable Development Finance, under conditions of effective operation of the capital market. 
At last, the forth chapter describes original holistic financial methodologies and creates "innovative holistic financial models" in order to taxonomize, evaluate and leverage the environmental, social and sustainable management policy in a sustainable capital market.

\section{Literature Review of the Sustainable Finance for the Capital Market}

The impact of environmental and social (and later sustainable) risks and opportunities on firm's shareholder value and the financial and investment system in the capital market has been systematically encountered since the early era of the $70^{\mathrm{s}}$ in the context of research on corporate social responsibility (Moskowitz, 1972; Vance, 1975; Alexander \& Buchholz, 1978; Spicer, 1978a, 1978b). Throughout the 1980s, especially after the escalation of environmental problems and social inequalities, we encounter significant research, which relates to the correlation of corporate environmental and social management policies with the firm's policies of capital markets (Cochran \& Wood, 1984; Mahapatra, 1984; Rosenberg, 1984; McGuire et al., 1988).

In 1990 era according to environmental news studies, Hamilton examines if the published by EPA-Toxics Release Inventory (TRI) data in June 1989 were really news for the journalists and the investors. In his conducted research he realized that the higher and the stable the TRI emissions were, the more important were the news for the journalists and the investors. He has also realized that when the publication of the TRI information went public, they had a negative impact on the shareholder value of firms with high and stable pollution elements. More concretely, his findings pointed abnormal returns of an average loss of 4.1 million in stock value for TRI firms on the day the pollution figures were published (Hamilton, 1995). Barth and McNichols paper aims to contribute to the understanding of financial reporting issues related to environmental liabilities. The authors claim that cost estimates are not predictable from public information, which does not preclude the possibility that firms have better private information that would allow them to provide estimates at an earlier point in the process (Barth et al., 1997). According to Hart and Ajula (1996), the following question arises: whether investments that target pollution reduction, increase investment costs and create competitiveness problems for firms or they raise the productivity and create competitive advantage for firms. In their research they prove that investments made by firms in order to prevent pollution, create in the first two years a significant problem in the bottom line of firms. This results to short term profit of businesses that do not invest in preventing pollution (Hart \& Ahuja, 1996). Hassel and coauthors present how environmental information is incorporated in the market value of listed Swedish companies and they claim that environmental efforts increase the competitive advantage of firms and improve financial returns to the investors (Hassel et al., 2001). Lorraine and coauthors, examine whether environmental performance publicity (either good or 
bad) affects the shareholder value of firms and they reach the conclusion that stock markets respond to this information and more particular, they indicated the correlation of environmental penalties with the shareholder value of firms (Lorraine et al., 2004). The Model Portfolio Analysis and the Multiple Regression Analysis used by financial science as techniques to investigate business situations that may cause long-term changes in the capital market. Feldman and coauthors suggest, that environmental improvement is recognized by the investing community and leads to a real decrease of business expected risk (lower beta), which comes together with a rise of stock market value of about 5\% (Feldman et al., 1997). Yamashita and coauthors correlate the environmental conscientiousness scores with the shareholder value of firms and they reach the conclusion that US capital markets reward the environmental conscientiousness scores of firms (Yamashita et al., 1999). King and Lenox examined 652 American processing companies during 1987-1996, in order to discover a relatively low relation between environmental pollution and the financial valuation of firms. They have also claimed, that a firm's fixed characteristics and strategic position might cause this correlation (King \& Lenox, 2001). Heinkel and coauthors, analyzed the effect of environmental, ethical and social investment funds on corporate behavior in a risk-averse, equilibrium setting and concluded that the basic motive that will affect companies that pollute, is the fraction of funds controlled by green investors. According to their model and their empirical data, more that $20 \%$ of green investors are required to cause reforms to the behavior of pollutants companies (Heinkel et al., 2001). Koellner and coauthors present the basic principles, methods of a comparative sustainability rating that should support the investors and their investing decisions in an independent and objective way (Koellner et al., 2005). Halkos and Sepetis, in their research study, plan and implement a holistic financial model that correlates environmental and social policy with microeconomic and macroeconomic factors that have an impact on the financial performance of Greek firms and determine that the environmental and social policies of Greek firms are recognized by investors. They recognize that there is a positive correlation of firms environmental performance and the shareholder value and that investors reward the best environmental performance of firms, with a raise of the shareholder value (Halkos \& Sepetis, 2007).

Molina-Azorın, go through the literature review, in order to examine the effect of environmental management in the financial performance of firms and conclude that the results of those studies are mixed, as companies, industries and countries vary. Moreover, they claim that most of the studies point out a significant positive correlation between environmental management and financial performance off firms (Molina-Azorín et al., 2009). According to Margolis and coauthors, the empirical studies have examined the correlation of corporate social performance (CSP) and corporate financial performance (CFP) for more than 35 years. In the after-analysis of the literature review, 192 results were revealed, that have been presented in 167 studies. The final result is positive and points a posi- 
tive, but not very strong correlation. They have specialized their analysis in nine categories of corporate social performance and reached the conclusion that the financial performance of companies is not negatively affected by corporate social performance (Margolis et al., 2009). In the literature review of Albertini, regarding the relationship between corporate environmental performance and financial performance, is revealed the many of the results are contradictive (positive, neutral, negative). Nevertheless, she claims that in most of relate studies (after-analysis of 52 studies for a period of 35 years) is revealed that environmental performance improves financial performance and that this correlation depends on the environmental and financial performance measures, the regional difference, the activity sector and the duration of research (Albertini, 2013). In their literature review, Clark and coauthors, use an improved after-analysis and they categorize more than 190 different relevant research. In their analysis they highlight the correlation between firms sustainability practices and financial performance. In the first part, they examine $88 \%$ of the research and they reach the conclusion that firms with strong sustainability practices show better operational performance, which is finally translated in increasing cash flows. The second part of their study proves, that wise firms sustainable practices have a positive impact on investing performance. This study finally proves that sustainable responsibility of companies and profitability are not always incompatible factors, but are completely complementary (Clark et al., 2015).

Many market participants now pay close attention to firms environmental, social and governance (ESG) policies. According to the relevant study of Sepetis and coauthors in 2011, as well other studies, it is claimed that firms shall be taxonomized and evaluated according to environmental, social and corporate governance criteria. Moreover, they have suggested a holistic financial evaluation model for environmental, social and corporate governance (Sepetis et al., 2011). Gillan and coauthors analyze how environmental, social and governance (ESG) rating correlates with the operational performance of firms, their performance, their compensation practices, their trading with the institutional investors and finally the evaluation. In their analysis they conclude that operational performance, efficiency and value of firms are positively correlated with the evaluation of ESG factors. Nevertheless, they mention that institutional investors prefer companies with good evaluation of their corporate governance (Gillan et al., 2010). Gunnar et al. (2015) paper, extracts all provided primary and secondary data of previous academic review studies and examine the relationship between environmental, social and corporate governance criteria (ESG) and corporate financial performance (CFP). They find out that scholars and investors have published more that 2000 empirical studies and a number of critical studies regarding this relationship. They reach the conclusion that $90 \%$ of their studies find a non-negative relationship between environmental, social and corporate governance investment (ESG) and corporate financial performance (CFP). The most important, the biggest majority of those studies report positive findings. 
They point out that the positive impact of environmental, social and corporate governance investment (ESG) in corporate financial performance seems to be stable during the time (Gunnar et al., 2015). According to Eccles and Klimenko (2019), business leaders understand that they should play a crucial role confronting emergency challenges, such as the climate change. But many of them, believe that pursuing a sustainability program is against the wishes of their stakeholders (Eccles \& Klimenko, 2019).

New financial products and services with environmental, social and sustainable central issues have been developed, while environmental, social and governance issues (ESG) have been incorporated into general lending, insurance and investment strategies. According to Piney and coauthors in 2019, in the last 3 years a great progress has been made towards the incorporation of environmental, social and corporate governance issues (ESG) in the capital market. For this reason, investors' role and those responsible for environmental, social and sustainable funds is very important for promoting environmental, social and corporate governance issues (ESG) in firms and the capital market (Piney et al., 2019). The financial markets are almost spontaneously playing a central and critical role in implementing the principle of sustainable development. In the financial market, many business organizations (firms, banks, insurances etc.) make contracts and carry out a vast variety of transactions. The decisions and strategies that are accomplished spontaneously affect environmental conservation, social equity and economic development. From this point of view, the financial market designs and implements policies to enable these business organizations bear sustainable practices. A distinct tendency is already evident to transcend spontaneity and follow consciously selected similar strategies and practices. Although since 2003, Sepetis and coauthors support that, the absence of a universally accepted standard method to record environmental and social information is still hindering the integration of theory and practices, into a coherent policy and management instrument. For example, the common practice of manipulating "bad" and "good" news in public reports, as well as the biased and incomplete disclosure of information about environmental and social issues still reinforces the uncertainty of stakeholders' decisions (e.g. the investors' selection of portfolio, Banks and Insurance's lending). Nevertheless, this kind of information is obviously crucial for designing effective decision by financial stakeholders (Sepetis et al., 2005). Busch and coauthors examine in which extend financial markets strengthen and make sustainable business practices easier. The authors point out that their current role is rather "mediocre". They conclude to the result, that in the "old paths" there is a paradox situation, where on the one hand the financial market participants incorporate more and more environmental, social and corporate governance (ESG) criteria in their investing decisions and on the other hand, as long as their organizing abilities are concerned, there does not seem to be a turn towards more sustainable practices. The authors spot two main challenges in the field of sustainable financial services and in- 
vestments that are related to entering new paths that may help overcome this situation. First of all, reorientation to a long-term example for sustainable financial services and investments is very important. Second, the environmental, social and corporate governance (ESG) data must become more trustworthy (Busch et al., 2015).

A number of new regulatory and legislative regulations have been invented by government or other auditing financial bodies (e.g. the European Union and the Capital Market Commission, SEC etc.) and have been compulsorily or voluntarily adopted in order to classify, evaluate, and evaluating the weight of the environmental, social and sustainable information in the capital market (UN Sustainable Stock Exchanges (SSE), 2018). The operation of stock market is more effective, when the level and credibility of information are available to the judgment of the investors. When new information becomes available in the market, the uncertainty of the investors decreases (for example the unemployment and the price levels) and show a willingness to re-establish, in a relevant way, their demands according to the new levels of uncertainty, as far as firm's value is concerned (Gupta \& Goldar, 2005). Asymmetric information and unregistered, unappreciated and widely publicized environmental, social and corporate governance information may create inefficient capital market conditions and create distrust in the investment community, thus undermining the sustainable capital market.

Since the 1980s, the scientific community has pointed out the interest of economic stakeholders in environmental and social information in making investment decisions. The authors also point out that in cases, where the accounting integration of environmental or social information is the result of voluntary initiative and not the result of mandatory arrangements (through predefined standards), then it cannot satisfy the basic principles of accounting standards and be considered reliable by institutional investment (Shane \& Spicer, 1983). According to Blacconiere and Pattem and Blacconiere and Northcutt the non-incorporation of environmental statement of a firm, as well as the distribution to the administration of inadequate accountability results, cause problems to operational process and more of these costs that could have been avoided (Blacconiere \& Pattem, 1994; Blacconiere \& Northcutt, 1997). These additional costs transfer through the capital market to stakeholders and as a characteristic result stakeholders have paid a large amount of USA environmental pollution (Ditz et al., 1995). Gray and Bebbington conclude that there is a rapid increase in the interest regarding environmental accounting. Nevertheless, they stress, that if environmental accounting is not incorporated properly in the accounting standards, then a real danger exists, that it will end do more bad that good (Gray \& Bebbington, 2000). Lamberton connects accounting with the upcoming term of sustainability and suggests a complete report model in firms that demands significant commitment of economic resources in order to succeed wide implementation by firms. Nevertheless, he supports that our failure to respond in this 
inter-connection and non-implementation of a holistic report model, allows companies to avoid accountability for their non-sustainable behavior (Lamberton, 2005). Orlitzky supports that CSR and environmental management systems certification may have harmful effects in buying shares for two reasons. First, corporate social responsibility is not related to the firm's economic fundamentals. Second, "opportunistic managers" are encouraged to distort the CSR information that are provided to capital market stakeholders. Every autonomous and non-taxonomized and non-transparent information by itself, makes it harder for the market participants to interpret accurately information regarding corporate social responsibility and financial performance. They also claim that this big "noise" that CSR information cause to the financial market usually attracts more noise transactions regarding companies CSR situation, which on their turn lead to an excessive market imbalance (among all listed firms) (Orlitzky, 2013). Krüger, supports that investors take into consideration and react negatively to negative facts and neutrally to positive CSR facts. Moreover, he claims that investors prefer positive performance and positive news for firms CSR with a negative CSR history. On the contrary, investors react negatively in positive CSR news, which are more likely to arise by false agents' information. He also believes, that CSR information, which is framed by economic and legal data, create for the investors more intense positive reactions (Krüger, 2015). Fernando and coauthors present the important consequences of corporate social responsibility through the analysis of institutional shareholders. In their analysis, they point out a sharp asymmetry between corporate policies that mitigate the firms exposure to environmental risk and those that enhance its perceived environmental friendliness ("greenness"). They conclude that institutional investors according to the risk management theory, avoid investing in high environmental risk exposure. Nevertheless, they point out that firms that increase "greenness" do not create shareholder value and are also shunned by institutional investors (Fernando et al., 2017).

Over time, an increasing number of environmental, social and sustainable performance frameworks and standards have been proposed in relation to how to report, on non-financial information, but there is still a constant market need for systematic, standardized and consolidated form and a common framework for this information. Bonson and Bednarova examined the extent to which Eurozone companies report on CSR indicators, according to the Integrated Scorecard Taxonomy Scoreboard of the Spanish Accounting and Business Association (AECA), as well as the indicators criteria that can influence its use. In their remarks, they stress that there is intensive use of corporate governance indicators, a moderate disclosure of environmental key performance indicators (KPIs) and a low use of social indicators (Bonson \& Bednarova, 2014). However, we must emphasize the underlying problem that the sustainable reports on "green-washing-information" hide. According to Siew, there is an enormous increase of interest by the stakeholders for environmental and social information 
that has led more and more firms to publish sustainable reports. Although some of the existing deficiencies with sustainable reporting tools (SRTs) include the lack of standardization which makes comparability difficult, corporations using SRTs to hide their actual practices, corporations deliberately manipulating stakeholders' perception through "green-washing" and the lack of attention to uncertainty in the assessment of sustainability performance (Siew, 2015). Credit rating assessments by financial analysts are also an important element of the proper functioning of financial markets, as they provide investors with credit rating assessments of firms and public organizations. Slager and Chapple analyze the role of intermediaries in financial markets in promoting corporate sustainability (SR). The responsible investment indicators (RI) are designed and implemented in order to reveal information to the investors and financial stakeholders for the corporate social responsibility of companies. In their study, they claim that companies that face exclusion threats and signaling are more likely to comply with the intermediary's criteria, and medium levels of engagement leads to higher levels of CSP. Moreover, they present the mechanisms that intermediaries and other financial actors could employ to foster greater corporate sustainability (Slager \& Chapple 2015).

Financial institutions analyzing environmental, social and sustainable creditworthiness operate in a market characterized by a high degree of concentration and adopt creditworthiness assessments based on relevant available information. Escrig-Olmedo and coauthors, claim that in the last years the financial analyst market have incorporate new criteria in their evaluation models to measure corporate environmental, social and sustainable efficiency. Nevertheless, a deeper analysis of the criteria shows that ESG evaluation agencies do not completely integrate the principles of sustainability in the procedure of corporate sustainable evaluation (Escrig-Olmedo et al., 2019). Clementino and Perkins, support that while an increasing number of companies are evaluated according to environmental, social and governance (ESG) criteria, however, a small number of studies have been conducted to evaluate the answers that companies provide for environmental, social and governance (ESG) issues. In their study, while they evaluate the answers that companies have been given for environmental, social and governance (ESG) issues, they claim that the corporate answers depend on managers' beliefs regarding the material benefits of adjusting to and scoring well on ESG ratings and their alignment with corporate strategy. Their study questions the evaluations of ESG rating agencies, as well as the positive performances of companies by ESG management policies and raises the attention of ESG rating agencies in evaluating corporate answers (Clementino \& Perkins, 2020).

UNEP FI has been working with banking, insurance and investment members to develop tools and methodologies to implement the recommendations of the Financial Stability Board's Task Force on Climate-related Financial Disclosures (TCFD) (UNEPFI, 2018). Moreover, two organizations, the Climate Disclosure Standards Board (CDSB) and the Sustainability Accounting Standards Board 
(SASB) participate in TCFD and try to incorporate environmental, social and sustainable information in accounting standards and the financial annual statement (SASB, 2017; SASB \& CDSB, 2019). By the end of 2016, the European Commission has designated a group of high-level experts for sustainable financing. In January $31^{\text {st }} 2018$, the group of experts has published the final report, which provided a complete vision regarding the way a sustainable financial strategy in the EU could be built. The report, supports that sustainable investing is about two major demands: 1) improving the contribution of finance to sustainable and inclusive growth by funding society's long-term needs; 2) strengthening financial stability by incorporating environmental, social and governance (ESG) factors into investment decision-making. The report provides eight basic suggestions, many horizontal suggestions and actions that target concrete fields of the financial system. This action plan is based in recommendations of the group in order to determine an EU strategy for sustainable funding. Moreover, this action plan for sustainable funding is part of the wider efforts for connecting funding with concrete needs of the European and global economy to the benefit of the planet and our society. Specifically, this Action Plan aims to: 1) reorient capital flows towards sustainable investment in order to achieve sustainable and inclusive growth; 2) manage financial risks stemming from climate change, resource depletion, environmental degradation and social issues; and 3) foster transparency and long-termism in financial and economic activity (EU Commission, 2018). On 18 June 2019, the European Commission's EU Technical Expert Group on Sustainable Finance (TEG) launched drafts for consultation on an EU Taxonomy, a voluntary EU Green Bond Standard and voluntary low-carbon benchmarks. UNEP FI is an observer to the TEG and contributed to the development of a taxonomy on land use. The EU Taxonomy is a classification system to help investors make informed investment decisions on environmentally friendly economic activities (EU Commission, 2019).

According to Porter and Kramer the concept of shared value targets the relationship between environmental, social and economic progress and has the power to unleash the next global development wave. Many big international companies believe in this correlation of common environmental, social and economic value and they support that the potential of shared value is just beginning (Porter \& Kramer, 2011).

\section{The Definition of Sustainable Capital Market for a Holistic Sustainable Finance Model}

Money, as seen on a sustainable perspective, and on the dominant International, European and National financial centers seem to be in a position, where it can leverage the upcoming environmental, social and corporate governance model in the capital markets. When the central bank and global insurance stakeholders or the global banks and the global institutional investors will be able to define the global model for the evaluation of sustainable risk, they will use the same en- 
vironmental, social and corporate governance evaluation financial risk model in all markets, then they will have the possibility of determining the global evaluation sustainable financial risk models. Nevertheless, it is stressed that today despite the financial analysis effort, in order to recognize and evaluate the environmental, social and sustainable financial risk of firms and of the market, big confusion is caused by the fact that the environmental, social or sustainable risk itself, is interpreted in many different ways inside the different types of financial stakeholders. Commercial banks are primarily interested in the environmental, social or general sustainable factors that affect the debtor's creditworthiness and the avoidance of additional environmental and social expenses. Investment banks are mainly interested in this parameter, as well as other environmental, social or sustainable effects that have an effect on the demand or the offer of the debt, bonds or mutual funds. Insurers are interested in taking over the insurance risk, only for the possibility of accidental environmental or social incidents that strive to avoid by following internal procedures, the interest rate of risk and uncertainty that their customers' environmental insurance demands can add by transferring them to the market. The regulatory investor or the manager of investment funds can take into account a broad number of sustainable financial risks, many of which are rather qualitative than quantitative. The term "environmental risk" creates to the common banker the tendency to connect it with the balance sheet data, the insurer with the environmental accidents and climate change. The institutions investors (pension funds, mutual funds) and investment fund managers are mainly interested in the consequences that environmental or social or corporate governance regulatory provisions have on the business procedures and less in the shaping of profitable investing decisions.

For these reasons, the system investors come first and demand that the environmental, social and corporate governance information to be taxonomized, be evaluated and published by the official accounting standards and financial statement of firms. Since the $80^{\text {s }}$ the scientific community has pointed the interest of individual economic stakeholders in the environmental or social information in taking their investment decisions. Moreover, the scientific community claims that in the case, where the accounting incorporation of environmental, social and sustainable information is a result of only a voluntary initiative and not a result of mandatory regulations (through predefined, models), then it can't satisfy the basic accounting principles standards and cannot be claimed as trustworthy by the institutional investors. A number of new regulatory and legislative regulations have been set by institution and governmental bodies (ex. the EU law for non-financial data), by auditing bodies (ex. IAS relevant to the ESG regulations of the capital market committee), by the market (ex. ESG Stock exchange benchmarks indexes, GRI) and have been mandatorily imposed or have been voluntarily adopted, in order to acknowledge and evaluate the capital market sustainability. These legislations and regulations are nevertheless still partial and can't be incorporated, as it is needed, in the framework of a holistic and 
properly designed strategy for the accounting standards and financial business statement. Despite the fact that many steps have been taken, is still obvious that there is a significant lack of official, regulatory or binding legal standards, for the taxonomy, the evaluation and the notification of environmental, social and corporate governance information in the capital market.

We are all aware of the power that money has, and today despite the rapid evolution of the last twenty years, there is still a constant commitment of the capital market bodies to the implementation of partial environmental, social and corporate governance policies for the recognition of sustainable performance of firms and the systematization of environmental, social or sustainable risk by individual and specialized in sustainable capital market bodies. Moreover, persisting in separating the environmental, social and sustainable dimension of firms and of the "green" or "social" or "sustainable" financial and investing stakeholders from the market, will actually lead the market towards asymmetric information and the creation of sustainable oligopolies. This will lead to a gradual "externalization" of the consequences of their decisions for the purchase or sale of capitalistic goods and service. Such practices discourage an economic development plan that becomes unacceptable in long term and turn the "Green" or "Social" or "Sustainable Financial Stakeholders" and the "Sustainable Shareholders" into fans of such an effort, which is the incorporation of environmental, social or sustainable policy in the capital market mechanism. In that way, the "green" or "social" and "sustainable" economic stakeholders and their positions become unacceptable.

Based on upon mentioned conclusions, it is proved that the three (key) sectors that can lead to the dissemination of sustainable policies in the operation of the capital market and bring new optimum efficiency conditions are the following:

1) The design of holistic fostering transparency and taxonomy for the long-term evaluation and notification of the sustainable financial risk models by the financial stakeholders. Sufficient regulatory safeguards should exist in every financial product that will satisfy the demand for a clearer sustainable evaluation.

2) The holistic taxonomy, the evaluation and notification of sustainable performance of environmental, social and corporate governance information (ESG) in the accounting standards and financial statement of firms and the creation of reliable financial (ESG) benchmark index during the decision making process.

3) The design of pioneer holistic financial models for taxonomy, the evaluation and notification of the environmental, social and corporate governance (ESG) statement, in the firms shareholder value.

The progress in these three key sectors will accelerate, if the deficiencies of the financial risk models and their involution with sustainable issues are examined in a systematic way, according to the generally accepted principles of international accounting standards and of corporate governance, as these are determined by international organizations and relevant regulations of each capital 
market. This, includes the development of a theoretical framework and a measurement system for the environmental, social and sustainable performance in the co-management of firms that is based in the decisions of impartial financial experts. On their turn they should present the arguments, should depict the needs of the funding investors in a more consistent and balanced way, by committing independent financial brands of institutional investors, promoting the environmental, social and sustainable relevant decisions.

In order to answer the question, in which extend is the implementation of environmental, social or sustainable management policies in contradiction or in harmony with the formation of shareholder value of firms and of the optimum efficiency of the capital market, we should proceed deeper and we should take into consideration the uncertainty of the capital market, regarding the formation of environmental, social or sustainable firm performance. What we propose, in order to calculate the evaluation of uncertain situations and the promotion of corrective actions, in order to lead the capital market to a new efficiency optimum, during which it will have incorporated the new era of sustainable information that is caused by the exogenous environmental, social or sustainable intervention, is to design and materialize a complete holistic environmental, social and sustainable management policy, according to the "new holistic sustainable financial models" for a "sustainable capital market".

Despite the impressive number of scientific research that has been analyzed by the current papers' literature review and which is characterized by a rather large variety of empirical research and by the low level of theoretical generalization in the financial science, the researcher asks himself: How can he/she organize himself in a way that can distinguish what is important or not and mainly to highlight "laws and normalities" that could act as a financial scientific theory?

Such a theory could outline the operational conditions of "Sustainable Capital Market" that is defined "as the capital market that promotes sustainable development with the implementation of mandatory or voluntary sustainable management policies. These policies have as a goal to develop sustainable innovation and sustainable technological progress and at the same time to leverage and promote sustainable firms management in the same firms and in the same financial stakeholders of the capital market, while at the same time they will contribute to the optimum efficiency of the capital market". This goal is succeeded, when the applied sustainable management policies are holistically designed and are identified for having as their main goal to not cause asymmetric information, price failures, and permanent oligopoly conditions in the market where they are applied.

Europe is far in the lead globally in achieving the SDGs. To better understand how the EU and its member states perform against the Sustainable Development Goals (SDGs,) the SDSN, in cooperation with IEEP, has developed an EU SDG Index and Dashboards that draws on far richer and more timely data than is available for the global SDG Index (Sachs et al., 2019). As described the EU SDG 
Index further in the methodology section and score each country's performance on a particular indicator on a scale from 0 to 100 , with 100 denoting the best possible score (Lafortune et al., 2018).

In order to view, how the upper mentioned approach of sustainable capital market is applied in action, let's just return to the dilemma that is examined in this article. If we accept, that limits of sustainable development goals of the achieved economic efficiency, social protection and environmental equal, which are set by local governmental-(country) or peripheral-(European Union) or International policy makers (Global Agreements), who are responsible for shaping sustainable policies and are registered in the European report for the Sustainable Development Goals in 2019, the following question arises: What would be the optimum sustainable management policies of firms that should have been motivated by the basic capital market stakeholders that manage the cost of the capital market? The question is how can the optimum efficiency of the capital market and for the financial and investors stakeholder circuit, involve conditions that are related to the social and environmental efficiency of the 17 sustainable development goals and through them, the optimum efficiency of the purchase of goods and services and promote simultaneously the sustainable development policies in the firms according to the targets that every European country has posed.

\section{The Holistic Sustainable Finance Model for the Sustainable Capital Market}

The Efficient Market Hypothesis argues that new information will be reflected in a stock's return. A firm risk profile can be distinguished into two components: the systematic and the specific or unique risk to the firm. The former form of risk reflects factors such as changes in interest rates, oil prices, inflation rates etc. that affect all firms in the market simultaneously. This implies, that investing in a more diversified portfolio cannot eliminate the risks posed by those factors. This is in line with modern financial portfolio theory, which concludes, that investors require a return for accepting only the systematic risk, as firm-specific risk can be diversified away. This reduction in systematic risk results to a decrease in the cost of financial capital and, for a given cash flow, in an increase in the stock price. A company's systematic risk is measured by its "beta", which is a measure of volatility of the stock under consideration to the overall market with the market's beta taking the value of 1 . In our case, if we take into consideration the results of the theoretical and the practical research that has been conducted on the topic, if we restrict our own research to firms that innovate in an environmental, social and corporate governance (ESG) evaluation, are listed on the stock market and negotiate according to the current capital market conditions, we shall conclude to a range of possible performances (positive-neutral-negative). Nevertheless, before we proceed to an analytical design of such a holistic sustainable financial model that will recognize and evaluate the effect of environmental, social 
or sustainable management policies in the shareholder value of firms we need to make the following remarks.

\subsection{Specification of the Macroeconomic Factors under Sustainable Capital Market Conditions}

Presuming that sustainable policy makers wish to improve the operation of the financial system and create optimum efficiency sustainable capital market conditions by leveraging the economic development, we suggest the following solutions in order to correct the capital market from the previous relevant optimum:

1) The design of holistic fostering transparency and taxonomy for the long-term evaluation and notification financial risk models of the environmental, social and sustainable risk by the direct financial stakeholders.

Presuming that the capital market leverage towards sustainability is mainly based on the definition of "sustainable capital market", as it was defined in the previous chapter, we propose the incorporation of a percentage of sustainable financial risk in the market discount interest rate, when this will be shaped in the European Commission's action plan for financing sustainable development by the European financing bodies, such as the European Central Bank. The banks discount interest rate is determined by the central financial organization mechanisms (such as the European Central Bank, World Bank) and has the possibility to accelerate the risk range of sustainable adjustment. We suppose that the risk range of the sustainable adjustment grade, reflects the percentage in which sustainable innovation (sustainable technology-expertise) reduces sustainable degradation that is produced with the per unit produced product of firms. The sustainable financial risk percentage is calculated by the average risk range sustainable performance of firms of the member states in the total of the European market, as this is determined by the annual progress reports for Sustainable Development Goals of the European Union and its member states. The sustainable interest rate of each member-state may adapt according to sustainable financial risk in the annual progress reports for Sustainable Development Goals or in each firms sector and will be financed respectively by the policies and the European Union goals, according to the grade of adjustment of sustainable development that wishes to achieve.

2) The mechanism optimization for taxonomy, the evaluation and the notification of environmental, social and sustainable performance of businesses, in order to promote transparent information in the sustainable capital market.

During the procedure of taking an investment decision, capital market is not based in voluntary progress reports, such as voluntary sustainable report, but mainly in mandatory data register of the firms in its official accounting standards, such as the balance sheet statement and the financial annual reports that are submitted to the Stock Exchange. In order to calculate market's and firms sustainable performance, all data (economic-social-environmental) that determine the definition of sustainability, in the official accounting standards and fi- 
nancial statement of firms should be registered and use during the evaluation phase a commonly accepted index of sustainable performance, which will derive from the firms official data. In order to determine sustainable performance of firms and of the market in total, we assume for the needs of the financial model, that inside a market, businesses obligatory register and evaluate their economic, the sustainable changes, the financial and non-financial data (Economic, Social, Environmental Data) in an originally holistic sustainable accounting standards, as conceded by SASB (2017), SASB and CDSB (2019). Given this assumption, all businesses in a market are obliged to register and recognize their sustainable situation (or in the case that we wish to leverage a business sector or a business portfolio), in order to be able to characterize them by the market as "sustainable" according to the calculation of relevant sustainable performance evaluation indexes.

According to this hypothesis the following indexes are normalize.

1) the Sustainable performance market index S.I.M $M_{r, t}$ is the normalized sustainable index of firms in a market $(r)$ in the current time $(t)$.

Where

$$
S . I . M_{\cdot r, t}=\frac{S . I_{r}-S . I_{\cdot r \text { min }}}{S . I \cdot_{r, \max }-S . I_{r_{r, \min }}} \mu \varepsilon \quad 0 \leq S . I . M_{\cdot_{r, t}} \leq 1
$$

and

$$
\text { S.I.r.t }=w_{E c c, t} Y_{E c o, t}+w_{E n v, t} E_{E n v, t}+w_{S o c, t} S_{S o c, t}
$$

with

$$
w_{E c o, t}+w_{E n v, t}+w_{S o c, t}=1 \text { and } w_{E c o, t} \geq 0, w_{E n v, t} \geq 0, w_{S o c, t} \geq 0
$$

- The sustainable market performance index in the current time is defined as $0 \leq$ S.I.M $M_{r, t} \leq 1$.

- When S.I.M $M_{r, t}=0$ the market is at the lowest range level of sustainable performance, an increase in the discount interest rate in such a percentage that will promote sustainable innovation is demanded.

- When S.I. $M_{r, t}=1$ the market is at the optimum range level of sustainable performance and there is no need to increase the discount interest rate in such a percentage that will promote sustainable innovation.

- When $0<$ S.I. $M_{r, t}<1$ then the market is under the optimum range level of sustainable performance and an increase of the discount interest rate is demanded, in such a percentage that will promote sustainable innovation.

- $S . I_{r, t}$ : is the average range rate of sustainable performances of firms in a market at the beginning of the year $t$,

- $S . I_{r, \text { min }}$ : is the lowest range rate that the sustainable firms index can take in a market at the end of the year $t$, and

- $S . I_{r, \max }$ : is the highest range rate that the sustainable firms index can take in a market at the end of year $t$,

- $Y_{E c o, t}$ : is the composite index of economic management of firms at year $t$, 
- $E_{E n v, i t}:$ is the composite index of environmental management of firms at year $t$,

- $S_{S o c, j t}$ : is the composite index of social management of firms at year $t$,

- $w_{E C o}$ : is the weighting range for the economic index of firms at year $t$,

- $w_{E n v}$ : is the weighting range for the environmental management index of firms at year $t$,

- $w_{\text {Soc }}$ : is the weighting range for the social management index of firms at year $t$.

2) the corporate Governance market index G.G.P. ${ }_{r, t}$ is applied with the principles, the criteria put by OECD, as well as with the rules that are valid in the each capital market and normalize in a market $(r)$ in the current time $(t)$ as following:

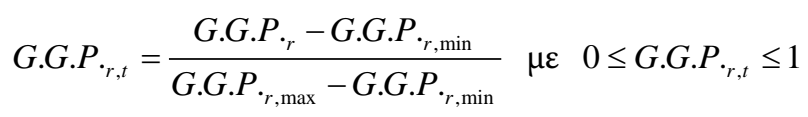

- The corporate governance market index in the current time is defined as $0 \leq$ G.G.P. $P_{r, t} \leq 1$

- When G.G.P., $P_{r, t}=0$ the market is at the lowest range level of corporate governance performance and an increase of the discount interest rate in such a percentage that sustainable innovation will be promoted is demanded.

- When G.G. $P_{r, t}=1$ the market is at the optimum range level of corporate governance performance and no increase of the discount interest rate in such a percentage that will promote sustainable innovation is demanded.

- When $0<$ G.G. $P_{r, t}<1$ then the market is under the optimum range level of corporate governance performance and an increase of the discount interest rate in such a percentage that will promote sustainable innovation is demanded.

3) In order to calculate Sustainable Interest rate in a market $(r)$ at the current time $(t)$ we need to follow:

The Sustainable interest rate $i_{\text {sust } \_ \text {r, }}$ : is the sustainable interest rate that equals with

$$
i_{\text {sust_r }, t}=i+f(\text { Sust_risk })
$$

and results, if for example the European Central Bank has concluded in the design of the discount interest rate an equivalent percentage that represents sustainable financial risk.

- Sustainable risk (Sust_risk ): Sustainable financial risk is calculated by reflection by the level of sustainable performance and the level of corporate governance of each market. That is the percentage of interest risk, which relates the existing sustainable performance and the level of corporate governance that prevails in the market.

$$
\text { Sustai_risk }_{r, t}=\sum_{t}^{r}\left(W_{S I M}(1-\text { S.I.M }) .+W_{G G P}(1-\text { G.G.P. })\right)
$$

- $W_{S I M}$ : the weighting range of the Sustainable performance market index. 
- $W_{G G P}$ : the weighting range of the Corporate Governance performance market index.

\subsection{The Description of the Holistic Sustainable Financial Model}

Taking the constantly increasing environmental, social or sustainable risk in total of the market for granted and the appearance of the increasing number of firms that concentrate capitals by the systematization of sustainable financial risk and the sustainable innovative products and services, we should ask ourselves, if environmental, social or sustainable management policies are against or harmonize with positive results, as far as the assessment of the shareholder value of firms is concerned?

In order to demonstrate the connections between changes in environmental, social and governance (ESG) risk and a shareholder value of firms, then we may consider firms that have publicly aligned their overall business mission with a number of environmental, social and governance objectives and publicly acknowledge that their excellent reputation is mainly due to its environmental, social and governance performance. In our empirical estimation we use the Capital Asset Pricing Model (hereafter CAPM) formulation expressed as

$$
\left(R_{j}-R_{f}\right)=\beta_{0 j}+\beta_{1 j}\left(R_{m}-R_{f}\right)+\varepsilon_{j}
$$

where, the stochastic disturbance term $\varepsilon_{j}$ represents the effect of unsystematic and diversifiable risk. We assume that $\varepsilon_{j}$ has a zero identically normally distributed mean. The term $R_{j}-R_{f}$ represents the risk premium for security $j$ while $R_{m}-R_{f}$ the overall market risk premium. Estimating $\beta_{1}$ by OLS is equivalent

$$
\beta_{1 j}=\frac{\sigma_{j m}}{\sigma_{m}^{2}}
$$

where, $\sigma_{j m}$ is the covariance between firm $j$ s return and that of the market in total and $\sigma_{m}^{2}$ is the variance of market's return.

Considering the CAPM model, as a special case of a more general model, we proceed to the implementation of the Arbitrage Pricing Model (hereafter APM). In this way, securities are allowed to respond differentially to macroeconomic shocks (or changes) such as unexpected oil price shocks or changes in the inflation rates. That is, the APM is formulated as:

$$
\begin{aligned}
\left(R_{j}-R_{f}\right)= & \beta_{0 j}+\beta_{1 j}\left(R_{m}-R_{f}\right)+\beta_{2 j} \text { Factor } 1+\beta_{3 j} \text { Factor }_{2}+\beta_{4 j} \text { Factor } 3 \\
& +\beta_{5 j} \text { Factor } 4+\beta_{6 j} \text { Factor } 5+\beta_{i j} \text { Factor }_{i}+\varepsilon_{t}
\end{aligned}
$$

According to our assumptions, as well as the hypothesis that have been previously expressed, we have separated the macroeconomic factors that affect the correlation that possibly sustainable management policies will try to pursue, under conditions of "sustainable capital market".

Factor 1 = Sustainable Interest Rate $i_{\text {sust_r,t }}$.

Factor 2 = Sustainable performance market index S.I.M $M_{r, t}$.

Factor $3=$ Price of oil. 
Factor $4=$ Industrial production

Factor 5 = Inflation rate respectively.

Calculate data

In our analysis we constructed an Environmental, Social and governance (ESG) constituted from SASB. The returns of the bonds and of the General Index of the Stock Exchange Market would be estimated as the ratio of the difference between the values in period $t\left(P_{t}\right)$ minus the values in period $t-1\left(P_{t-1}\right)$ over the values in period $t-1$. For the approximation of the main macroeconomic variables we use the consumer price index, the price of Brent oil and the index of industrial production. Following Berndt we construct first the rate of inflation, the growth rate in the real price of oil and the growth in industrial production and then from each constructed variable we subtract its corresponding sample mean (Berndt, 1991). Specifically, the rate of inflation (INFLRATE) is defined as the consumer price index (hereafter CPI) in period $t$ minus CPI in period $t-1$ divided by CPI in period $t-1$; the growth rate in the real price of oil (ROILPG) is defined as $\left[(\mathrm{ROILPG} / \mathrm{CPI})_{t}-(\mathrm{ROILPG} / \mathrm{CPI})_{t-1}\right] /(\mathrm{ROILPG} / \mathrm{CPI})_{t-1}$; and the growth in industrial production (INDPRG) is defined as the ratio of the difference in industrial production in period $t$ minus the industrial production in period $t-1$ over the industrial production in period $t-1$. The risk free rate refers to the interest of the Governmental Bond Yield.

In our last step we investigated the need to extend the model to cope with $\mathrm{ARCH}$ effects and risk as an explanatory variable. The most common used $\mathrm{ARCH}$ and GARCH models as intro introduced by Engle and Bollerslev take the conditional variance as a linear function of lagged conditional variances and squared residuals (Engle, 1982; Bollerslev, 1986). Theoretically these models are characterized by linearity as they imply an ARMA equation for the squared prediction errors $\left(u_{t}^{2}\right)$ allowing a full study of the distributional properties of $u_{t}$ as well as easier statistical inference.

$$
Y_{t}=X_{t} \beta+v_{t}
$$

where $X$ represents the vector of independent variables (and the lagged dependent variable), $\beta$ is a constant vector and $v_{t}$ the disturbance term. The latter is defined as

$$
v_{t}=\sigma_{t} Z_{t}, \quad Z_{t} \sim \text { i.i.d. } N(0,1), \quad \sigma_{t}^{2}=\gamma_{0}+\sum_{i=1}^{q} \gamma_{1 i} v_{t-1}^{2}+\sum_{j=1}^{p} \gamma_{2 j} \sigma_{t-j}^{2}
$$

where $p$ and $q$ are non-negative integers and $\quad \gamma_{1 i} \geq 0 \quad \forall i \geq 0, \quad \gamma_{2 i} \geq 0 \quad \forall j \geq 0$ and $\gamma_{0} \geq 0$ to secure a strictly positive conditional variance. The ARCH effect $\left(\alpha_{2 i}\right)$ shows the short-run persistence of shocks while the GARCH $\left(\beta_{2 i}\right)$ indicates the contribution of shocks to the long-run persistence.

Following Engle and Ng (1993) a joint diagnostic test for non-linear ARCH effects is performed.

The test relies on the following regression (Engle \& $\mathrm{Ng}$, 1993).

$$
\varepsilon_{i t}^{2}=a+b S_{t-1}^{-}+b_{2} S_{t-1}^{-} \varepsilon_{i, t-1}+b_{3}\left(1-S_{t-1}^{-}\right) \varepsilon_{i t-1}+c Z_{i}+e_{i}
$$


where $\varepsilon_{i t}$ are the standardized residuals, $S_{t-1}$ a dummy variable taking the value of 1 if $\varepsilon_{i t-1}$ is negative and 0 otherwise and $Z$ a vector of explanatory variables. The test statistic for this test is the LM statistic $\left(n * R^{2}\right) \sim X_{\alpha}^{2}$ with 3 degrees of freedom.

As the conditional variance in a GARCH formulation is a function of the magnitude of the lagged residuals and not their signs, this implies that one of the main restrictions of GARCH models is that they rely on a symmetric response of volatility to positive and negative shocks. Specifically, the GARCH formulation proposes a symmetrical treatment of the effects of these shocks on the conditional variance in such a way that the effect of negative and positive shocks on the conditional volatility to be identical.

It is argued that in financial time series, negative shocks increase volatility more compared to equal positive shocks. These asymmetries are usually attributed to leverage effects. A reduction in the value of a company's stock increases the firm's debt to equity ratio and the shareholder who bear the residual risk of the firm consider their future cash flows as more risky. Zakoian and Glosten and coauthors promote two popular asymmetric formulations may be used in case of asymmetries: the Threshold GARCH or TGARCH (Zakoian, 1991; Glosten et al., 1993). The Exponential GARCH or EGARCH proposed by Nelson (1991). A limitation of the latter is the fact that the effects on volatility of positive values relative to negative remain fixed in time.

The TGARCH is used here as it treats the asymmetric effects of shocks and presumes that negative shocks have a higher impact on volatility (and thus greater leverage) compared to positive shocks of similar magnitude. A TGARCH $(1,1)$ can be formulated as

$$
\sigma_{t}^{2}=\delta_{0}+\delta_{1} v_{t-1}^{2}+\delta_{2} \sigma_{t-1}^{2}+\delta_{3} v_{t-1}^{2} I_{t-1}
$$

where $I_{t-1}=1$ if $v_{t-1}=0$ and $I_{t-1}=0$ otherwise. If $\gamma>0$, then we may have a leverage effect.

The non-negativity conditions are $\alpha_{0} \geq 0, \alpha_{1} \geq 0, \beta \geq 0$ кal $\alpha_{1}+\gamma \geq 0$.

Thus the TGARCH's main advantage of the parameterization is that it takes into account asymmetries in volatility as well as the non-negativity of the parameters. This asymmetry is important, as volatility tends to be higher after a decrease than after an equal increase.

\section{Conclusion}

In this paper analysis is suggested that the results that have been reached by the academic, public political consultation and the capital market, present three key problems: 1) ambiguity has prevailed, as to what we define environmental, social or sustainable policy management of firms. This has been as a result to not be able to substantiate a common assumption regarding the sustainable finance risk models of firms in the capital market. Furthermore, the evaluated regulation for the credit ability CRA, should be amended in order to explicitly require the examination of the characteristics of environmental, social and sustainable per- 
formance in all credit rating assessments, 2) firms, financial stakeholders, shareholders and the state have significantly delayed to recognize the need of incorporating environmental, social and corporate governance factors in the firms operations, as well as to implement taxonomies, evaluation and notification with a commonly accepted sustainable accounting standard in the financial statement of the firms and 3) there is not a commonly accepted holistic taxonomy, evaluation and notification of sustainable financial risk models for the shareholder value of firms by the financial stakeholders.

These three problems result in the lack of a commonly accepted evaluation for the sustainable financial performance of firms and the capital market as whole and on the other hand in the lack of the collection of environmental, social and corporate governance financial data with commonly accepted financial methods. That means, that the range of sustainable performance evaluation of firms by the financial standards and the report benchmarks indexes, gets limited and creates asymmetric information, disbelief and conditions of inefficient operation in the capital market. These are three basic remarks, which the current Action Plan for sustainable development finance by the UN the European Commission and other financial institutions tries to solve.

This paper promotes innovation, as its main contribution in research is the correction of the failure of sustainable development in the capital market and the determination of a commonly accepted definition of "sustainable capital market", as it is defined and analyzed in the third chapter of the present paper and the creation of holistic policies of sustainable taxonomy, evaluation and notification of sustainable finance performance. With the formulation of the holistic sustainable policies taxonomies, evaluation and notification in a sustainable capital market level, we determine: 1) a sustainable interest rate that will evaluate sustainable risk in total, which is shaped by the policies and the sustainable development goals that have been set in the market. In order to determine "where we are" in relation to our goals and "where we want to go", 2) commonly accepted accounting standards for the taxonomy, evaluation and notification of sustainable performance of financial annual statement of firms in the capital market, 3) a commonly accepted and strictly implemented procedure of holistic sustainable finance model in the sustainable decision making of financial stakeholder, in order to ensure that CEOs and board of firms, the financial stakeholders and the shareholders are obliged to be aware of the sustainable firms performance, which is commonly co-decided for the well-being of the business, the society and the planet.

A financial model of holistic policies for sustainable management is suggested, "under the optimum conditions of sustainable capital market". Nevertheless, for its implementation, the synchronized action of all involved bodies in the "sustainable capital market" is demanded. Presently, the lack of environmental, social and corporate governance data, holistically integrated in the accounting and financial statement off firms, have not allowed us to further test the original fi- 
nancial model in the capital market "under sustainable conditions" and the extraction of useful predictions during the decision making process.

Finally, the purpose of this paper is to suggest a holistic sustainable financial model according to macroeconomic factors, that will eventually try to shape sustainable management policies, under conditions of "sustainable capital market", will taxonomize, evaluate and predict with the assistance of simulation models and the range of "sustainable interest rate", the possibility of "sustainable adjustment". Moreover, sustainable policies will leverage sustainable capital market, and the holistic sustainable financial models, in order to justify between others the choice of a sustainable financial policy, under optimum efficiency in the capital market.

\section{Acknowledgements}

This study has been done within the framework of the Postgraduate Health and Social Care Management programme of the University of West Attica.

\section{Conflicts of Interest}

The author declares no conflicts of interest regarding the publication of this paper.

\section{References}

Albertini, E. (2013). Does Environmental Management Improve Financial Performance? A Meta-Analytical Review. Organization \& Environment, 26, 431-457. https://doi.org/10.1177/1086026613510301

Alexander, J. G., \& Buchholz, R. A. (1978). Corporate Social Responsibility and Stock Market Performance. Academy of Management Journal, 21, 479-486. https://doi.org/10.5465/255728

Barth, M. E., McNichols, M. F., \& Wilson, G. P. (1997). Factors Influencing Firms' Disclosures about Environmental Liabilities. Review of Accounting Studies, 2, 35-65. https://doi.org/10.1023/A:1018321610509

Berndt, E. R. (1991). The Practice of Econometrics: Classic and Contemporary. Boston, MA: Addison-Wesley.

Blacconiere, W. G., \& Northcutt, D. W. (1997). Environmental Information and Market Reactions to Environmental Legislation. Journal of Accounting, Auditing \& Finance, 12, 149-178. https://doi.org/10.1177/0148558X9701200203

Blacconiere, W. G., \& Pattem, D. M. (1994). Environmental Disclosures, Regulatory Costs, and Changes in Firms Value. Journal of Accounting and Economic, 18, 357-477. https://doi.org/10.1016/0165-4101(94)90026-4

Bollerslev, T. (1986). Generalized Autoregressive Conditional Heteroskedasticity. Journal of Econometrics, 31, 307-327. https://doi.org/10.1016/0304-4076(86)90063-1

Bonson, E., \& Bednarova, M. (2014). CSR Reporting Practices of Eurozone Companies. Revista de Contabilidad, 18, 182-193. https://doi.org/10.1016/j.rcsar.2014.06.002

Busch, T., Bauer, R., \& Orlitzky, M. (2015). Sustainable Development and Financial Markets: Old Paths and New Avenues. Business \& Society, 55, 303-329. https://doi.org/10.1177/0007650315570701 
Clark, G. L., Feiner, A., \& Viehs, M. (2015). From the Stockholder to the Stakeholder: How Sustainability Can Drive Financial Outperformance. SSRN Electronic Journal. https://papers.ssrn.com/sol3/papers.cfm?abstract id=2508281 https://doi.org/10.2139/ssrn.2508281

Clementino, E., \& Perkins, R. (2020). How Do Companies Respond to Environmental, Social and Governance (ESG) Ratings? Evidence from Italy. Journal of Business Ethics. https://doi.org/10.1007/s10551-020-04441-4

Cochran, P., \& Wood, R. (1984). Corporate Social Responsibility and Financial Performance. Academy of Management Journal, 27, 42-56. https://doi.org/10.5465/255956

Ditz, D., Ranganathan, J., Darry, R., \& Banks, R. D. (Eds.) (1995). Green Ledgers: Case Studies in Corporate Environmental Accounting. Washington DC: World Resources Institute W.R.I.

Eccles, G. R., \& Klimenko, S. (2019). The Investor Revolution. Harvard Business Review, 97, 106-116.

Engle, R. F., \& Ng, V. K. (1993). Measuring and Testing the Impact of News on Volatility. Journal of Finance, 48, 1749-1778. https://doi.org/10.1111/j.1540-6261.1993.tb05127.x

Engle, R. L. (1982). Autoregressive Conditional Heteroscedasticity with Estimates of the Variance of United Kingdom Inflation. Econometrica, 50, 987-1007. https://doi.org/10.2307/1912773

Escrig-Olmedo, E., Fernández-Izquierdo, M. Á,. Ferrero-Ferrero, I., Rivera-Lirio, J. M., \& Muñoz-Torres, M. J. (2019). Rating the Raters: Evaluating How ESG Rating Agencies Integrate Sustainability Principles. Sustainability, 11, 915-935.

https://doi.org/10.3390/su11030915

EU Commission (2019). EU Technical Expert Group on Sustainable Finance (TEG). The EU Taxonomy to Define Sustainable Economic Activities. https://ec.europa.eu/info/publications/sustainable-finance-technical-expert-group en

Feldman, S. J. Soyka, P. A., \& Ameer, P. (1997). Does Improving a Firm’s Environmental Management System and Environmental Performance Result in a Higher Stock Price? Journal of Investing, 6, 87-97. https://doi.org/10.3905/joi.1997.87

Fernando, S. C., Sharfman, M. P., \& Uysal, B. V. (2017). Corporate Environmental Policy and Shareholder Value: Following the Smart Money. Journal of Financial and Quantitative Analysis, 52, 2023-2051. https://doi.org/10.1017/S0022109017000680

Gillan, S., Hartzell, J., Koch, A., \& Starks, L. (2010). Firms' Environmental, Social and Governance (ESG) Choices, Performance, and Managerial Motivation. Unpublished working paper, Texas Tech University and University of Texas at Austin. http://www.pitt.edu/ awkoch/ESG\%20Nov\%202010.pdf

Glosten, L. R., Jagannathan, R., \& Runkle, D. E. (1993). On the Relation between the Expected Value and the Volatility of the Nominal Excess Return on Stocks. The Journal of Finance, 48, 1779-1801. https://doi.org/10.1111/j.1540-6261.1993.tb05128.x

Gray, R., \& Bebbington, J. (2000). Environmental Accounting, Managerialism and Sustainability: Is the Planet Safe in the Hands of Business and Accounting? Advances in Environmental Accounting \& Management, 1, 1-44. https://doi.org/10.1016/S1479-3598(00)01004-9

Gunnar, F., Busch, T., \& Bassen, A. (2015). ESG and financial Performance: Aggregated Evidence from More than 2000 Empirical Studies. Journal of Sustainable Finance \& Investment, 5, 210-233. https://doi.org/10.1080/20430795.2015.1118917

Gupta, S., \& Goldar, B. (2005). Do Stock Markets Penalize Environment-Unfriendly Behaviour? Evidence from India. Ecological Economics, 52, 81-95. 
https://doi.org/10.1016/j.ecolecon.2004.06.011

Halkos, G., \& Sepetis, A. (2007). Can Capital Markets Respond to Environmental Policy of Firms? Evidence from Greece. Ecological Economics, 63, 578-587. https://doi.org/10.1016/j.ecolecon.2006.12.015

Hamilton, J. T. (1995). Pollution as News: Media and Stock Markets Reactions to the Toxics Release Inventory Data. Journal of Environmental Economics and Management, 28, 98-113. https://doi.org/10.1006/jeem.1995.1007

Hart, S., \& Ahuja, G. (1996). Does It Pay to Be Green? An Empirical Examinations of the Relationships between Emissions Reduction and Firm Performance. Business Strategy and the Environment, 5, 30-37.

https://doi.org/10.1002/(SICI)1099-0836(199603)5:1<30::AID-BSE38>3.0.CO;2-Q

Hassel, L., Nilsson, H., \& Nyquist, S. (2001). The Value Relevance of Environmental Performance. European Accounting Review, 14, 41-61. https://doi.org/10.1080/0963818042000279722

Heinkel, R., Kraus, A., \& Zechner, J. (2001). The Effect of Green Investment on Corporate Behavior. Journal of Financial and Quantitative Analysis, 36, 431-449. https://doi.org/10.2307/2676219

King, A., \& Lenox, M. (2001). Does It Really Pay to Be Green? An Empirical Study of Firm Environmental and Financial Performance: An Empirical Study of Firm Environmental and Financial Performance. Journal of Industrial Ecology, 5, 105-116. https://doi.org/10.1162/108819801753358526

Koellner, T., Weber, O., Fenchel, M., \& Scholz, R. (2005). Principles for Sustainability Rating of Investment Funds. Business Strategy and the Environment, 14, 54-70. https://doi.org/10.1002/bse.423

Krüger, P. (2015). Corporate Goodness and Shareholder Wealth. Journal of Financial Economics, 115, 304-329. https://doi.org/10.1016/j.jfineco.2014.09.008

Lafortune, G., Fuller, G., Moreno, J., Schmidt-Traub, G., \& Kroll, C. (2018). SDG Index and Dashboards. Detailed Methodological Paper. Paris: Bertelsmann Stiftung and Sustainable Development Solutions Network.

Lamberton, G. (2005). Sustainability Accounting-A Brief History and Conceptual Framework. Accounting Forum, 29, 7-26. https://doi.org/10.1016/j.accfor.2004.11.001

Lorraine, N., Collison, J., \& Power, D. (2004). An Analysis of the Stock Market Impact of Environmental Performance Information. Accounting Forum, 28, 7-26.

https://doi.org/10.1016/j.accfor.2004.04.002

Mahapatra, S. (1984). Investor Reaction to Corporate Social Accounting. Journal of Business Finance and Accounting, 11, 29-40. https://doi.org/10.1111/j.1468-5957.1984.tb00054.x

Margolis, J. D., Elfenbein, A. H., \& Walsh, J. P. (2009). Does It Pay to Be Good... and Does It Matter? A Meta-Analysis of the Relationship between Corporate Social and Financial Performance. SSRN Electronic Journal, 1-68.

https://doi.org/10.2139/ssrn.1866371

McGuire, B. J., Sundgren, A., \& Schneeweis, T. (1988). Corporate Social Responsibility and Firm Financial Performance. Academy of Management Journal, 31, 854-872.

Molina-Azorín, J. F., Claver-Cortés, E., Lopez-Gamero, M. D., \& Tari, J. J. (2009). Green Management and Financial Performance: A Literature Review. Management Decision, 47, 1080-1100. https://doi.org/10.1108/00251740910978313

Moskowitz, R. M. (1972). Choosing Socially Responsible Stocks. Business and Society Review, 1, 71-75. 
Nelson, D. B. (1991). Conditional Heteroskedasticity in Asset Returns: A New Approach. Econometrica, 59, 347-370. https://doi.org/10.2307/2938260

Orlitzky, M. (2013). Corporate Social Responsibility, Noise, and Stock Market Volatility. Academy of Management Perspectives, 27, 238-254. https://doi.org/10.5465/amp.2012.0097

Piney, C., McCorkle, C., Lawrence, S., \& Lau, S. (2019). Sustainability in Capital Market: A Survey from Current Progress and Practices (pp. 3-40). High Meadows Institute.

Porter, M., \& Kramer, M. R. (2011). Creating Shared Value: How to Reinvent Capitalism and Unleash a Wave of Innovation and Growth. Harvard Business Review, 12, 1-17.

Rosenberg, B. (1984). Prediction of Common Stock Investment Risk. Journal of Portfolio Management, 11, 44-53. https://doi.org/10.3905/jpm.1984.408984

Sachs, J. D., Kroll, C., Schmidt-Traub, G., Lafortune, G., \& Fuller, G. (2019). Sustainable Development Report 2019. Transformations to Achieve the Sustainable Development Goals. Gütersloh and New York: Bertelsmann Stiftung and Sustainable Development Solutions Network.

SASB (2017). SASB Rules of Procedure Sustainability Accounting Standards Board. https://www.sasb.org/wp-content/uploads/2019/05/SASB-Rules-of-Procedure.pdf

Sepetis, A., Katsikis, I., \& Nikolaou, I. (2011). Environmental, Social and Corporate Governance: A Framework of Evaluation for Financial Stakeholders. Journal of Regional Socio-Economics \& Business (JRSEB), 1, 5-23.

Sepetis, Á., Nikolaou, I., \& Sophoulis, C. M. (2005). Environmental and Social Accounting Method Assists Financial Market to Contribute to Sustainable Development. 9th International Conference on Environmental Science and Technology, Rhodes, Greece, 1-3 September 2005, B-853-B-859.

Shane, P. B., \& Spicer, B. H. (1983). Market Response to Environmental Information Produced Outside the Firm. The Accounting Review, 58, 521-538.

Siew, R. Y. J. (2015). A Review of Corporate Sustainability Reporting Tools (SRTs). Journal of Environmental Management, 164, 180-195. https://doi.org/10.1016/j.jenvman.2015.09.010

Slager, R., \& Chapple, W. (2015). Carrot and Stick? The Role of Financial Market Intermediaries in Corporate Social Performance. Business \& Society, 55, 398-426. https://doi.org/10.1177/0007650315575291

Spicer, B. H. (1978a). Market Risk, Accounting Data and Companies Pollution Control Records. Journal of Business, Finance and Accounting, 5, 67-83. https://doi.org/10.1111/j.1468-5957.1978.tb00175.x

Spicer, B. H. (1978b). Investors, Corporate Social Performance and Informational Disclosure: An Empirical Study. Accounting Review, 53, 94-111.

SASB \& CDSB (2019). Implementation Guide Introduces the Task Force on Climate-Related Financial Disclosures' (TCFD). The SASB Foundation (SASB) and CDP Worldwide on behalf of the Climate Disclosure Standards Board (CDSB) https://www.cdsb.net/sites/default/files/tcfd good practice handbook web a4.pdf

UN Sustainable Stock Exchanges (SSE) (2018). How Securities Regulators Can Support the Sustainable Development Goals. A Sharing of Experiences. https://sseinitiative.org/wp-content/uploads/2018/10/SSE-Regulator-Report-compresse d.pdf

UNEPFI (2018). Changing Course: A Comprehensive Investor Guide to Scenario-Based Methods for Climate Risk Assessment, in Response to the TCFD.

https://www.unepfi.org/wordpress/wp-content/uploads/2019/05/TCFD-Changing-Cou 
rse-Oct-19.pdf

Vance, S. (1975). Are Socially Responsible Corporations Good Investment Risks? Management Review, 64, 18-24.

Yamashita, M., Sen, S., \& Roberts, M. C. (1999). The Rewards for Environmental Conscientiousness in the U.S. Capital Markets. Journal of Financial and Strategic Decisions, 12, 73-82.

Zakoian, J. M. (1991). Threshold Heteroskedastic Models. D.P. INSEE.

EU Commission (2018). Financing a European Economy. Final Report 2018 by the High-Level Expert Group on Sustainable Finance Secretariat Provided by the European Commission.

https://ec.europa.eu/info/sites/info/files/180131-sustainable-finance-final-report en.pdf 